\title{
Spectrophotometric determination of trimethoprim using 2,4-dinitro-1-fluorobenzene reagent
}

\section{Theia'a N. Al-Sabha}

Department of Chemistry

College of Education

University of Mosul

Received

10/1r/ 2009

\author{
Intesar A. Hamody \\ Department of Chemistry
}

College of Education for Girls

University of Mosul

\section{Accepted}

16 / 02 / 2010

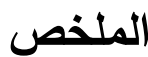

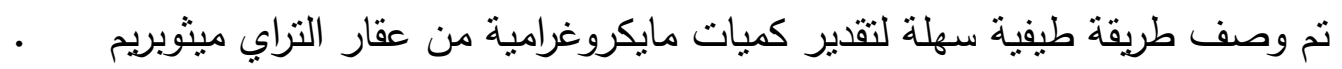

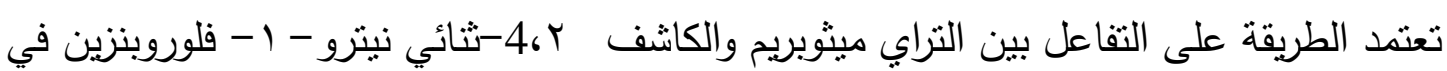

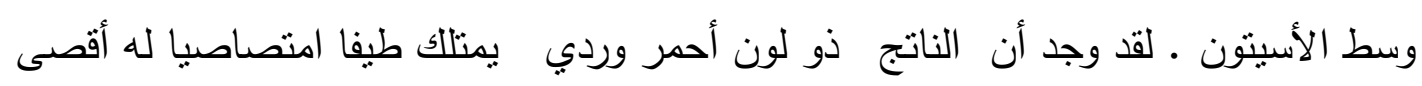

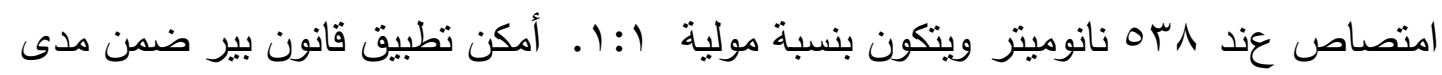

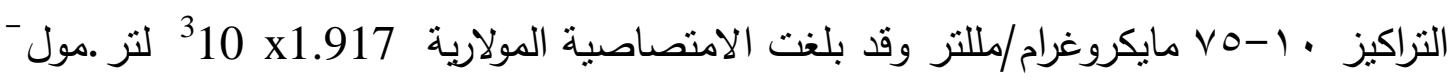

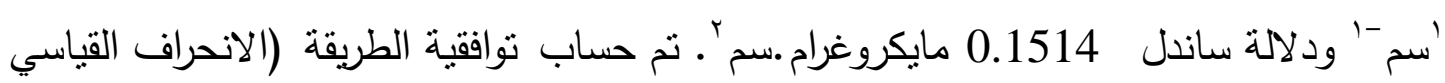

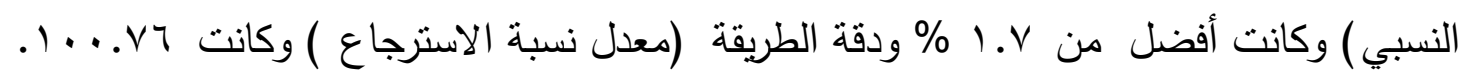

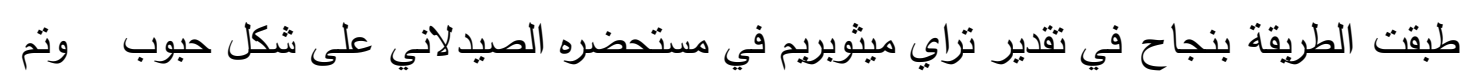

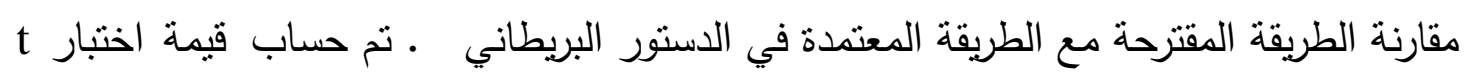

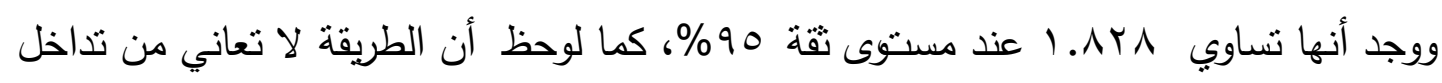

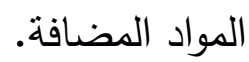

\begin{abstract}
A simple spectrophotometric method for the determination of trimethoprim (TMP) in pure form and in its pharmaceutical formulation has been described. The method is based on the reaction of TMP with 2,4-dinitro-1-fluorobenzene reagent (DNFB) in acetone medium to give a highly rosy red colored product with maximum absorption at $538 \mathrm{~nm}$ with a molar ratio of $1: 1$. Beer's law is obeyed in the range $10-75 \mu \mathrm{g} / \mathrm{ml}$ with molar absorptivity of $1.917 \times 10^{3} 1 . \mathrm{mol}^{-1} . \mathrm{cm}^{-1}$ and Sandell's sensitivity
\end{abstract}


of $0.1514 \mu \mathrm{g} / \mathrm{cm}^{2}$. Precision (RSD) better than $1.7 \%$ and accuracy (average recovery \%) is $100.76 \%$. The suggested method has been applied to dosage forms as tablets and compared with the pharmacopoeial method, t-test is evaluated and found 1.828 at $95 \%$ confidence limit. The results show that there is no interference are present in commercial dosage forms.

Keywords: $\quad$ Spectrophotometry; 2,4-dinitro-1-fluorobenzene; $\quad$ TMP; spectrophotometry.

\section{Introduction}

Trimethoprim[2,4-diamine-5-(3,4,5-trimethoxybenzyl) pyrimidine; (TMP)] (scheme 1), is known as a folic acid antagonist and is commonly used in combination with sulfonamides to treat gastrointestinal and respiratory tract infections and as a powerful bacteriostatic agent. TMPsulfonamide formulations are also widely used as growth promoters. Residues of TMP may therefore occur even if the elimination time is short (elimination half-life is $5.5 \mathrm{~h}$ for TMP in plasma) [1,2].

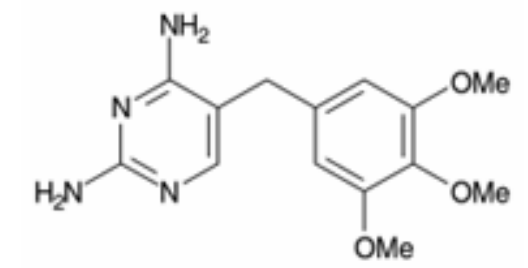

$$
\mathrm{M} . \mathrm{Wt}=290.3
$$

Schem e 1. Structure formula of trim ethoprim

Many analytical techniques have been employed for the determination of TMP. The generally used analytical techniques are electrochemical methods [3], selective membrane electrode [4], differential pulsed polarography and cyclic voltammetry [5], TLC [6,7], a TLC-densitometry [8], HPTLC [9], ion pair chromatography [10] and spectrodensitomety [11], a biomimetic bulk acoustic wave sensor was fabricated and applied for the determination of TMP in organic phase based on a molecular imprinting polymer [12]. In USP 26, HPLC is used for determination of TMP [13]. However; the determination of TMP and other drugs in biological systems, either individual or combined have been described by HPLC method [14-16].

Few spectrophotometric methods have been described for determination of TMP in the literature. These methods are based on using bromothymol blue, bromocresol green and alizarin red $\mathrm{S}$ as $\pi$-acceptors [17], oxidation of TMP by persulfate in alkaline medium [18] and ionpair formation with bromophenol blue [19]. Other spectrophotometric methods are used for determination of TMP in a mixture with 
sulphametoxazole depending upon derivative [20-22] extractive[23] and bivariate calibration [24] spectrophotometric methods.

The present work describes the spectrophotometric determination of TMP based on the reaction of the amine group with DNFB reagent in acetone medium.

\section{Experimental}

\subsection{Apparatus}

Shimadzu (UV-210) Double Beam Spectrophotometer with $1.0 \mathrm{~cm}$ silica cells was used to measure the absorbance. Heating of solutions is carried out on a water bath of frost instruments, LTD. The reading of $\mathrm{pHs}$ made on a PW 9420 philips pH meter supplied with an electrode type CE $10-12 \mathrm{pH}$. Weighing is carried out on a balance type of Mettler H 54 AR.

\subsection{Reagents}

Analytical grade chemicals, acetone was used. Standard solution of TMP $(250 \mu \mathrm{g} / \mathrm{ml})$ in acetone was prepared. $1 \times 10^{-2} \mathrm{M}$ of DNFB (Sigma Co.) was prepared in acetone.

\section{General procedure}

Increasing volumes containing $0.2-1.5 \mathrm{ml}$ of $250 \mu \mathrm{g} / \mathrm{ml}$ (i.e. $10-75$ $\mu \mathrm{g} / \mathrm{ml}$ ) of TMP in pure form and $2 \mathrm{ml}$ of DNFB were added in 5-ml volumetric flask and left for $40 \mathrm{~min}$ at $60^{\circ} \mathrm{C}$. Then the solutions are cooled to room temperature and diluted to the mark with acetone solvent The absorbance was measured at $538 \mathrm{~nm}$ against the reagent blank.

\section{Analysis of tablets}

Ten tablets (each tablet containing $80 \mathrm{mg}$ TMP) were accurately weighed and pulverized. A portion of the fine and homogenized powder equivalent to $80 \mathrm{mg}$ TMP was accurately weighed and dissolved in about $15 \mathrm{ml}$ of acetone. The solution was shaken thoroughly for about $10 \mathrm{~min}$. and the residue was filtered through Whatmann no. 42 filter paper into 25 $\mathrm{ml}$ volumetric flask. The filtrate was diluted to the mark by repeated washing with acetone. The filtrate was diluted to get a $250 \mu \mathrm{g} / \mathrm{ml}$ solution of TMP. An aliquot containing 10 to $75 \mu \mathrm{g} / \mathrm{ml}$ was taken and the procedure as described above was followed. The absorbance was measured at $538 \mathrm{~nm}$. The quantity per tablet was calculated from the standard calibration curve.

\section{Results and discussion}

In the preliminary investigation work, it was found that DNFB reagent reacted with TMP in acetone medium forming a rosy red colored product having two bands, the first band is a doublet width band with 
maximum absorption at $380 \mathrm{~nm}$ and the reagent blank gave high absorption at this wavelength, the second band is a symmetrical band and more sharper than the doublet with maximum absorption at $538 \mathrm{~nm}$ which is the reagent blank almost gave no absorption at this wavelength, (Fig.1).Therefore the second band at $538 \mathrm{~nm}$ has been considered in subsequent experiments.

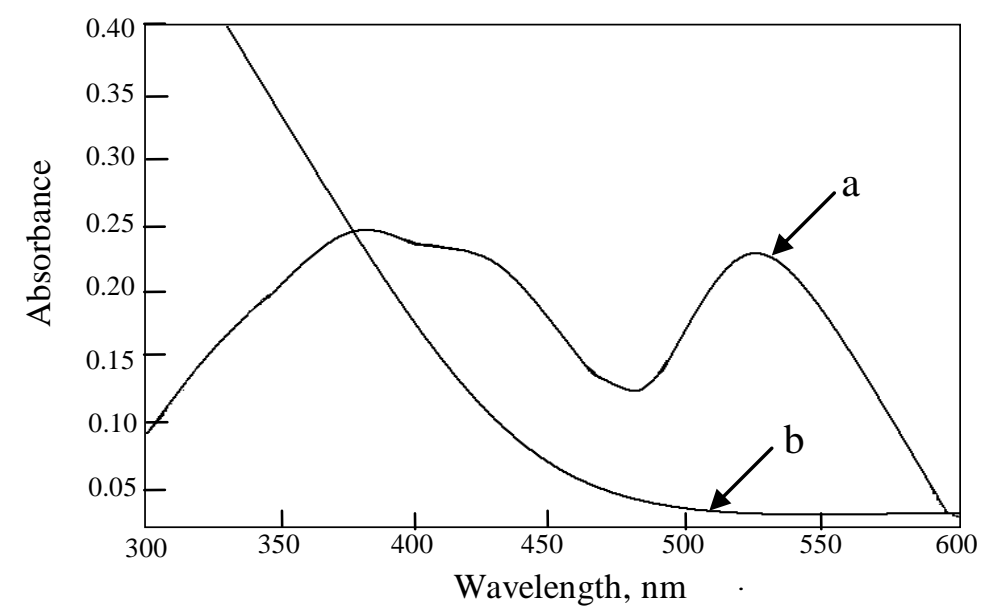

Fig.1. Absorption spectra of (a) $60 \quad \mu g \quad \mathrm{ml}^{-1}$ TMP product with $2 \mathrm{ml}$ of $0.01 \mathrm{M}$ DNFB reagent aganist reagent blank and (b) reagent blank against acetone.

\subsection{Study of the optimum reaction conditions}

The effect of various parameters on the absorption intensity of the colored product was studied and the reaction conditions are optimized.

\subsubsection{Effect of solvent}

Effect of various solvents such as ethanol, chloroform, acetonitrile, acetone and water for the sensitivity of the produced colored product were examined. It was found that acetone gave a rosy red colored product with maximum absorption at $538 \mathrm{~nm}$, whereas other solvents gave low response with maximum absorption less at $400 \mathrm{~nm}$, (Fig.2). Therefore acetone was chosen as organic medium in subsequent experiments.

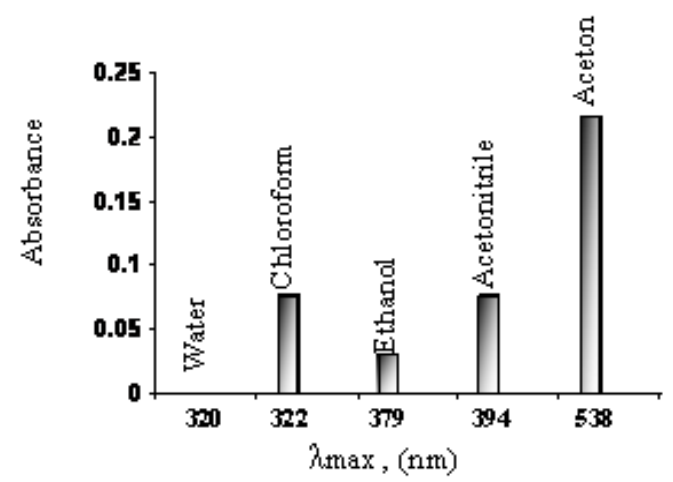

Fig. 2. Effect of solvent on the absorption of $50 \mu \mathrm{g} / \mathrm{ml}$ trimethoprime 


\subsubsection{Effect of $\mathrm{pH}$ and buffer solutions}

The effect of $\mathrm{pH}$ on the absorption of the product was studied using different $\mathrm{pHs}$ of $\mathrm{HCl}$ or $\mathrm{NaOH}$ ranged from 2 to 11.6. As seen in (Fig.3), it was found that the product formed with maximum absorption in the absence of acid or base ( $\mathrm{pH}$ 7.4). Therefore different buffers such as borate, bicarbonate, phosphate and barbiton of the $\mathrm{pH} 7.4$ were prepared and their effects on the sensitivity were examined. It was found that all of them decrease the absorbance.

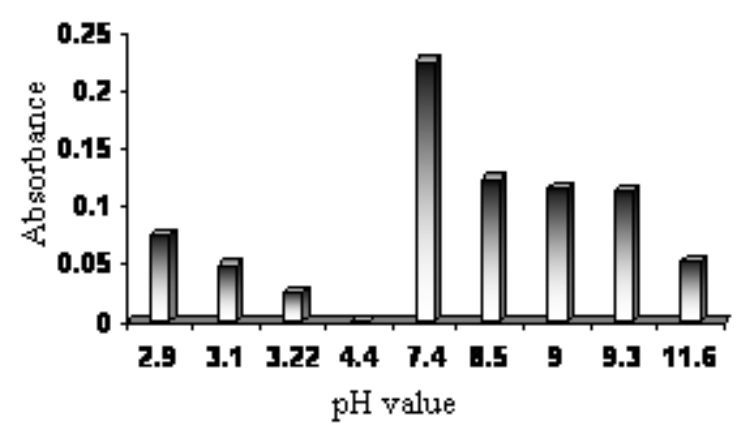

Fig. 3 Effect of $\mathrm{pH}$ on the absorption of $50 \mu \mathrm{g} / \mathrm{ml}$ trimethoprime

\subsubsection{Effect of temperature and reaction time}

The reaction time was determined by following the color development at room temperature and in thermostatically controlled water-bath at different temperatures. The absorbance was measured against reagent blank treated similarly. It was observed that the sensitivity reached maximum after $40 \mathrm{~min}$ at $60^{\circ} \mathrm{C}$ and stable for $40 \mathrm{~min}$ after which it begun slowly fade, (Fig.4). This temperature and reaction time was chosen for the color development in subsequent experiments. 


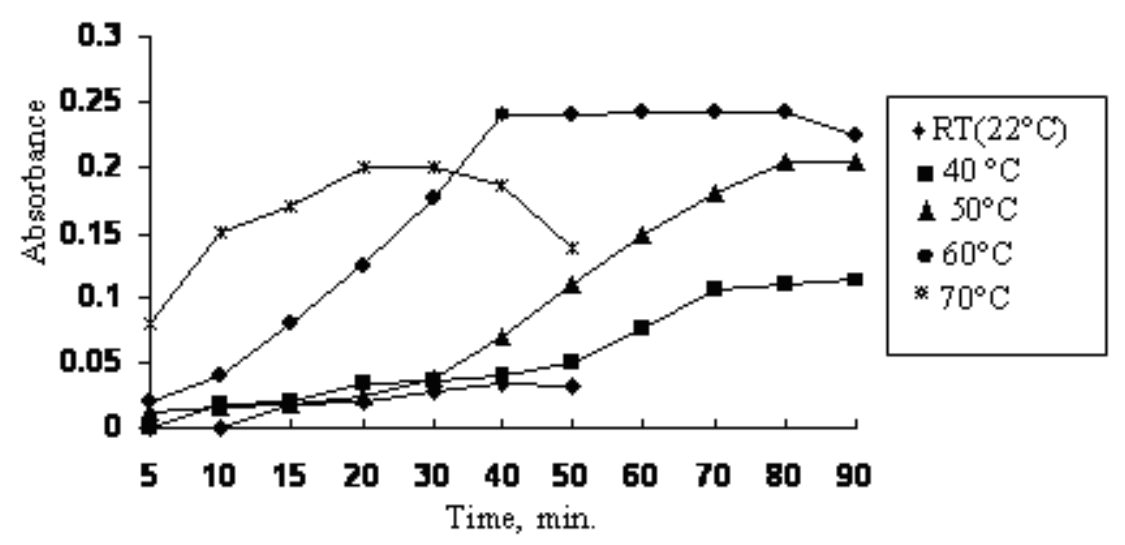

Fig.4. Effect of temperature and developing time on the absorbance of $50 \mu \mathrm{g} / \mathrm{ml}$ trimethoprime

\subsubsection{Effect of DNFB reagent amount}

The influence of DNFB concentration on the color intensity was studied by measuring the absorbance at the specified wavelength in the standard procedure for solutions containing the same drug amount but varying amount of DNFB. A volume of $2 \mathrm{ml}$ of $1 \times 10^{-2} \mathrm{M}$ in a total volume of $5 \mathrm{ml}$ was found to be sufficient for full color development (Fig.5).

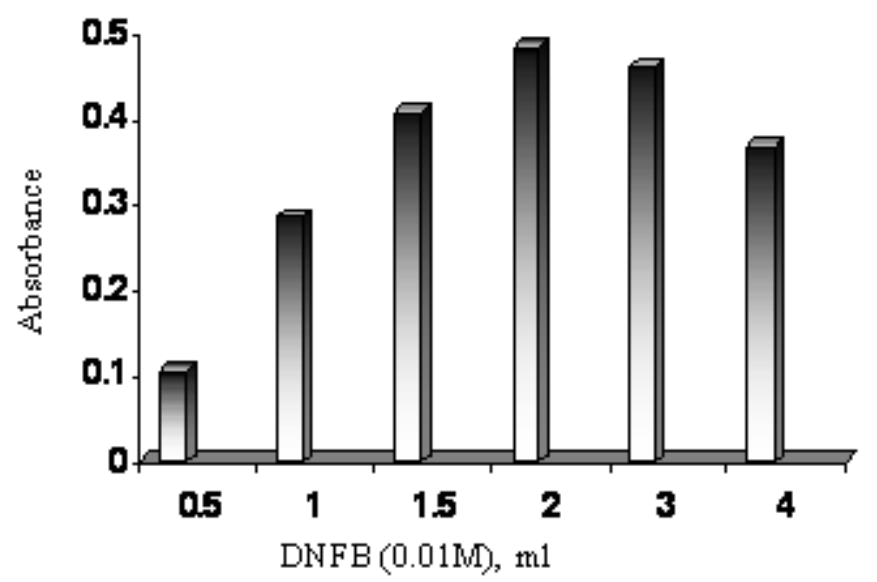

Fig. 5 Effect of $1 \times 10^{-2} \mathrm{M}$ amount on the absorption intensity of $50 \mu \mathrm{g} / \mathrm{ml}$ trimethoprime

\subsection{Precision and accuracy}

The accuracy and precision of the proposed method was established by measuring the content of trimethoprim in pure form at three different concentration levels for six replicates at 25, 50 and $75 \mu \mathrm{g} / \mathrm{ml}$, (Table 1). The values of relative standard deviation and mean percent recovery obtained by the proposed method can be considered to be very satisfactory. 
Table 1 : Precision and accuracy of the proposed method

\begin{tabular}{|c|c|c|c|}
\hline $\begin{array}{c}\text { Amount } \\
\text { added } \mu \mathrm{g} / \mathrm{ml}\end{array}$ & $\begin{array}{c}\text { Recovery* } \\
(\%)\end{array}$ & $\begin{array}{c}\text { Average } \\
\text { recovery } \\
(\%)\end{array}$ & RSD $^{*}$ \\
\hline 25 & 100.3 & \multirow{2}{*}{100.76} & 1.642 \\
\hline 50 & 100.7 & & 0.912 \\
\hline 75 & 101.3 & & 0.649 \\
\hline
\end{tabular}

* Average of six determinations.

\subsection{Quantification and Analytical Data}

The absorbance of the formed product conform with Beer's law in the concentration range $10-75 \mu \mathrm{g} / \mathrm{ml}$ (Fig.6). The molar absorptivity is $1.917 \times 10^{3} 1 . \mathrm{mol}^{-1} \mathrm{~cm}^{-1}$. The linearity was represented by the regression equation and the corresponding correlation coefficient for TMP determined by the proposed method were shown in Table 2 .

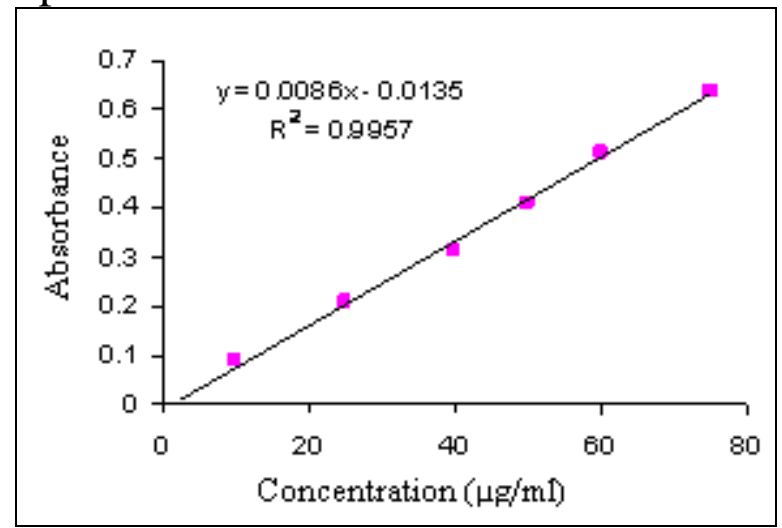

Fig.6. Calibration graph of TMP drug

Table 2. Summary of optical characteristics and statistical data for the proposed method

\begin{tabular}{lc} 
Parameters & Values \\
\hline$\lambda_{\max }(\mathrm{nm})$ & 538 \\
Beer's law $(\mu \mathrm{g} / \mathrm{ml})$ & $10-75$ \\
Molar absorptivity $\left(1 . \mathrm{mol}^{-1} \mathrm{~cm}^{-1}\right)$ & $1.917 \times 10^{3}$ \\
${\text { Sandell index }\left(\mu \mathrm{g} / \mathrm{cm}^{2}\right)}^{*}$ & 0.1514 \\
Regression equation $(\mathrm{Y})$ & \\
Slope $(\mathrm{b})$ & 0.0086 \\
Intercept $(\mathrm{a})$ & -0.0135 \\
Correlation coefficient $\left(\mathrm{R}^{2}\right)$ & 0.9957 \\
Average recovery \% & 100.43 \\
Average relative standard & \\
deviation $(\mathrm{RSD} \%)^{\star *}$ & 1.067 \\
Temperature $\left({ }^{\circ} \mathrm{C}\right)$ & 40 \\
Development time $(\min )$. & 60 \\
Stability period $(\min )$. & 30 \\
Final pH & 7.4
\end{tabular}


${ }^{*} \mathrm{Y}=\mathrm{ac}-\mathrm{b}$ where $\mathrm{C}$ is the concentration of analyte $(\mu \mathrm{g} / \mathrm{ml})$ and $\mathrm{Y}$ is the absorbance unit.

${ }^{* *}$ Calculated fro six determinations.

\subsection{Interference}

The extent of interference by some excipients which often accompany pharmaceutical preparations were determined by measuring the absorbance of solutions containing $40 \mu \mathrm{g} / \mathrm{ml}$ of TMP and various amounts(in $\mathrm{mg}$ ) of excipients in final volume of $5 \mathrm{ml}$. It was found that the studied excipients do not interfere in the present method, even when present in large excess. An error of 5.0\% in the absorbance readings was considered tolerable. Typical results are given in Table 3.

Table 3: Effect of excipients for assay of TMP

\begin{tabular}{|l|c|c|}
\hline excipients & $\begin{array}{c}\text { Amount added } \\
(\mathrm{mg})\end{array}$ & $\begin{array}{c}\text { Relative error } \\
\text { (E\%) }\end{array}$ \\
\hline \multirow{4}{*}{ Acacia } & 0.1 & -0.55 \\
\cline { 2 - 3 } & 0.2 & -2.50 \\
\cline { 2 - 3 } Glucose & 0.4 & -1.39 \\
\cline { 2 - 3 } & 0.1 & -3.23 \\
\cline { 2 - 3 } & 0.2 & -2.11 \\
\hline \multirow{3}{*}{$\begin{array}{l}\text { Sodium } \\
\text { chloride }\end{array}$} & 0.4 & 0.10 \\
\hline \multirow{3}{*}{ Starch } & 0.1 & -2.76 \\
\cline { 2 - 3 } & 0.2 & -0.69 \\
\cline { 2 - 3 } & 0.4 & -0.57 \\
\cline { 2 - 3 } & 0.1 & -1.59 \\
\hline
\end{tabular}

\section{Application}

The proposed method was successfully applied to determine TMP in pharmaceutical preparations as tablets. The obtained results were compared statistically by a Student's $t$-test for accuracy with the official method [25] (depending on potentiometric titration of pure drug dissolved in anhydrous acetic acid with perchloric acid) at the $95 \%$ confidence level with five degrees of freedom, as cited in Table 4 . The results showed that the experimental $t$-test (1.828) less than the theoretical value (2.776), indicating that there was no significant difference between the proposed method and official method.

Table 4: Assay of TMP tablet $(80 \mathrm{mg})$ in pharmaceutical formulation by the proposed and official methods

\begin{tabular}{|c|c|c|c|c|}
\hline $\begin{array}{c}\text { Procedure } \\
\text { applied }\end{array}$ & $\begin{array}{c}\text { Pharmaceutical } \\
\text { preparation }\end{array}$ & $\begin{array}{c}\text { Drug amount } \\
\text { taken }\end{array}$ & $\begin{array}{c}\text { Recovery * } \\
(\%)\end{array}$ & $\begin{array}{c}\text { Drug content } \\
\text { found per tablet }\end{array}$ \\
\hline
\end{tabular}




\begin{tabular}{|c|c|c|c|c|}
\hline & & $(\mu \mathrm{g} / \mathrm{ml})$ & & $(\mathrm{mg})$ \\
\hline \multirow{4}{*}{$\begin{array}{c}\text { Proposed } \\
\text { method }\end{array}$} & \multirow{3}{*}{$\begin{array}{c}\text { Tablet } \\
(80 \mathrm{mg})\end{array}$} & 10 & 97.62 & 78.09 \\
\cline { 3 - 5 } & & 20 & 98.88 & 79.10 \\
\cline { 3 - 5 } & & 25 & 98.56 & 78.84 \\
\cline { 3 - 5 } & & 75 & 96.32 & 77.05 \\
\hline $\begin{array}{c}\text { Official } \\
\text { method [25] }\end{array}$ & \multirow{2}{*}{ Tablet (80 mg) } & 25 & 102.08 & 77.79 \\
\hline
\end{tabular}

${ }^{*}$ Every reading is an average of three determinations.

\section{Stoichiometric Relationship}

The molar ratio of the product formed between the studied drug and the reagent used was investigated applying the continuous variation (Job's) method using equimolar solutions of the drug and reagent $\left(1 \times 10^{-3} \mathrm{M}\right)$. The results indicated that the product was formed in the ratio of 1:1 (Fig. 6). This finding supports that the interaction of the studied drug and the reagent used takes place at only one site which was the more sterically free terminal basic primary amino group.

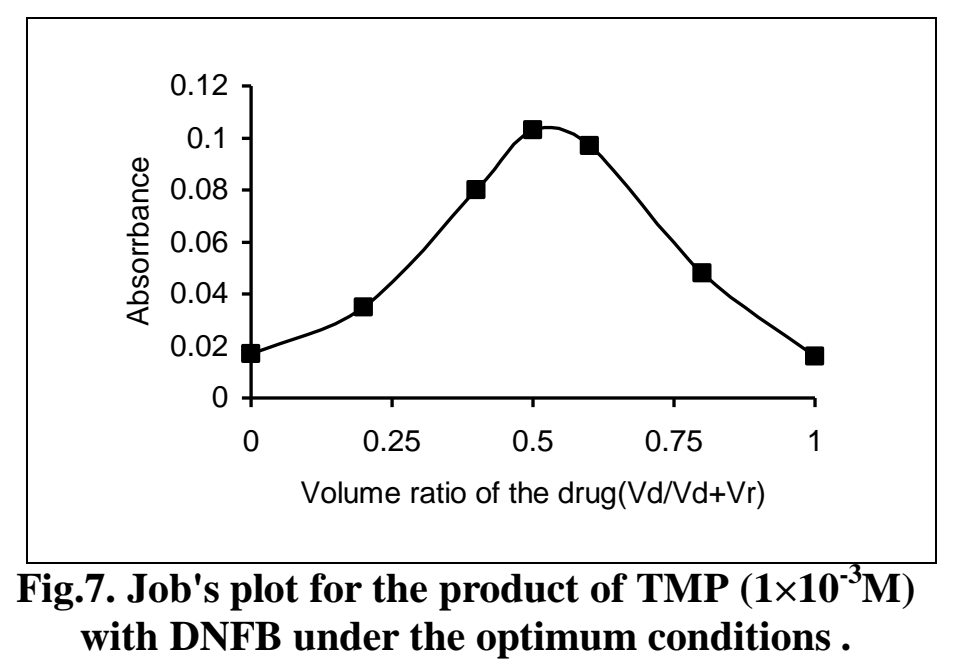

\section{Reaction mechanism:}

The reaction of DNFB with drugs that own a free primary amine group results in the formation of coloured products ${ }^{[28]}$. This reaction was first introduced by Sanger ${ }^{[30]}$ as means for determination of the DNA sequence. Based on the Job's method of continuous variation, it was found that TMP interacted with the DNFB in ratio of $1: 1$. This result indicates that the reaction between the drug and the reagent used takes place at only one site which was the more sterically free terminal amino group. The reaction is typical nucleophilic substitution and proceeds through an intermediate product as shown in scheme 2 . 


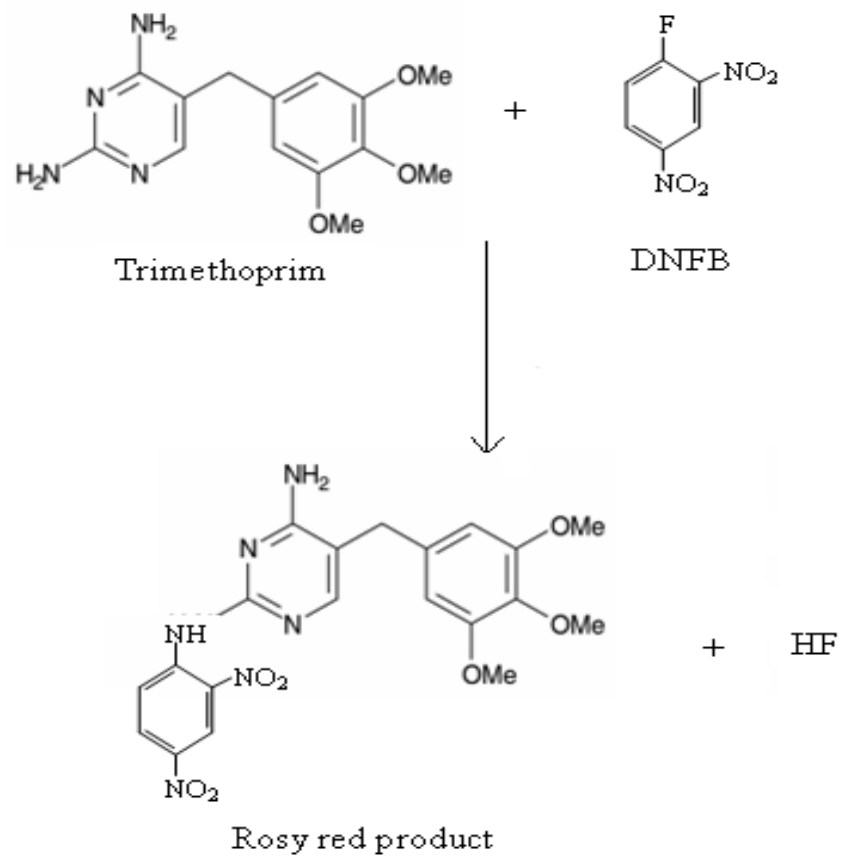

Scheme 2. Reaction mechanism for TMP with DNFB reagent

\section{Conclusions}

A spectrophotometric method has been developed for the determination of trace amounts of TMP based on its reaction with DNFB reagent in acetone medium. The proposed method is simple and precise and does not require solvent extraction step. However; the method required heating step to increase the reaction speed and sensitivity in addition to use of organic medium. The method was applied successfully for determination of TMP in its pharmaceutical tablets and compared favorably with the official method.

\section{References}

1) Garwacki S., Lewicki J., Wiechetek M., Grys S., Rutkowski J. and Zaremba M., A study of the pharmacokinetics and tissue residues of an oral trimethoprim/sulphadiazine formulation in healthy pigs, J. Vet. Pharmacol. Ther.,1996, 423-430.

2) Qureshi S. Z., Helaleh M.I.H., Rahman N. and Q. Jamhour R. M. A., Spectrophotometric determination of trimethoprim by oxidation in drug formulations., Fresenius J. Anal. Chem., 1997,357, 10051007.

3) Yarnitzky C. and Smyth W.F., Square wave polarographic and voltammetric analysis of selected electroreducible drugs, Int. J. Pharm., 1991,75,161-169.

4) Yao SZ., Shiao J. and Nie LH., A trimethoprim-selective membrane electrode, Talanta, 1987 ,34, 983-986.

5) Chatten L. Stanley Pons G., B. and McLeod P., Electrochemical determination of trimethoprim, Analyst, 1982, 107, 1026-1031 
6) Sigel CW., Grace ME., Nichol CA. and Hitchings GH., Specific TLC determination of trimethoprim and sulfamethoxazole in plasma, J. Pharm. Sci., 1974, 63,1212-5.

7) Danijela A. et al., Solid-phase extraction and TLC quantification of enrofloxacin, oxytetracycline, and trimethoprim in wastewater, J. planar chromatogr., 2006,19, 129-134 .

8) Tomankova H., Vasatova M. and Zyka J., A TLC-densitometric determination of sulphonamide chemotherapeuticals, Anal. Lett., 1988, 21, $2227-2240$.

9) Knupp1G., Pollmann1H. and Jonas D., An improved HPTLC method for the rapid identification and quantification of sulfonamides, Chromatographia, 986, 22, 21-24.

10) Watson ID., Shenkin A, McIntosh SJ, Cohen HN., Assay of trimethoprim in serum and urine by means of ion pair chromatography, Clin. Chem., 1980,26, 1791-1795.

11) Sigel C.W et al., Specific tlc determination of trimethoprim and sulfamethoxazole in plasma, J. Pharm. Sci., 2006, 63, $1202-1205$.

12) Yao S., P. Hui, Liang C., Wu Y., and Nie L., Biomimetic bulk acoustic wave sensor for determination of trimethoprim in the organic phase based on a molecular imprinting polymer, Anal. Sci., 2000, 16,211-215.

13) The United States Pharmacopeia - The National Formullary (USP26-NF21), Asian Edition 2003 United States Pharmacopeia Inc, Rochvelle, MD, USA., 1738-1742.

14) de Paula F.C.C.R., de Pietro A.C. and Cass Q.B., Simultaneous quantification of sulfamethoxazole and trimethoprim in whole egg samples by column switching high-performance liquid chromatography using restricted access media column for on- line sample clean-up., J. . Chromatogr. A, 2008, 1189, . 221-226.

15) Gallego J. M. and Arroyo J. P., Simultaneous determination of dexamethasone and trimethoprim by liquid chromatography, J. Pharm. Biomed. Anal., 2002, 30, 1255-1261

16) Lakkanatinaporn, P. and Matayatsuk, C., Simultaneous HPLC method for determination of sodium trimethoprim phenylpropanol disulphonate and sodium sulfaquinoxaline in veterinary drugs, Songklanakarin J. Sci. Technol., 2004, 26, 850-854.

17) El-Ansary A. Issa YM. Selim W., Spectrophotometric determination of trimethoprim in pure form and in pharmaceutical preparations using bromothymol blue, bromocresol green and alizarin red $\mathrm{S}$, Analytical Letters. 1999, 32, 955-969.

18) Qureshi S. Z. , Helaleh M. I., Rahman N. and Jamhour R. M., Spectrophotometric determination of trimethoprim by oxidation in drug formulations, Fresenius J. Anal. Chem., 357 (1997) 1005-1007

19) Sanyal AK, Laha D., Rapid colorimetric assay of TMP and sulfamethoxazole in pharmaceuticals, J Assoc Off Anal Chem. 1983 Nov; 66(6): 1447-9.

20) Lin LM., Determination of trimethoprim and sulfamethoxazole in pharmaceutical preparations by non-relative component referencemultiplier derivative spectrophotometry, Yao Xue Xue Bao. 1991, 26,858-63. [Article in Chinese]. 
21) Sun Z., Li R., Li Y., Wang K., Zhang Q. and Zhou J., Determination of sulfamethoxazole in compound sulfamethoxazole tablet by first derivative ratio spectrometry, Guang Pu Xue Yu Guang Pu Fen Xi. 2001, 21, 713-5. [Article in Chinese].

22) Othman S., Multicomponent derivative spectroscopic analysis of sulfamethoxazole and trimethoprim, Inter. J. Pharm., 1990, 63, 173176.

23) Vachek J. and Kakac B., Extractive spectrophotometric determination of trimethoprim in a mixture with sulfamethoxazole, Cesk Farm., 1976, 25, 186-7.

24) López-Martínez L et al., Simultaneous determination of binary mixtures of trimethoprim and sulfamethoxazole or sulphamethoxypyridazine by the bivariate calibration spectrophotometric method, J. Pharm. Biomed. Anal., 2002, 30, 7785.

25) British Pharmacopoeia, CD room (2005). The Stationary Office, London.

26) Georgiou C., Koupparis M. and Hadjiioannou T., Flow Injection stopped-flow kinetic spectrophotometric determination of drugs, based on micellar-catalysed reaction 1-fluoro-2,4-dinitro benzene, Talanta, 1991, 38, 689-696.

27) Sanger F., The free amino groups of insulin, Biochem. J., 1945, 39, 507-515. 